\title{
A Psicologia em História da Loucura De Michel Foucault ${ }^{\star}$
}

\author{
Fernando de Almeida Silveira $\star \star$ \\ Richard Theisen Simank ${ }^{\star \star \star}$
}

\begin{abstract}
Resumo
Michel Foucault investiga "a história das relações que o pensamento mantém com a verdade" e desnaturaliza corpo, alma e psiqué considerando-os invenções histórico-discursivas, as quais só têm sentido se inseridas em determinados arranjos epistêmicos de produção de verdades, no caso, o surgimento das ciências humanas. Esta pesquisa estuda a ordem do discurso foucaultiano sobre a Psicologia em sua fase arqueológica, no livro História da Loucura, com o intuito de oferecer subsídios para a compreensão da história dos discursos da Psicologia, no que se refere à edificação do sujeito e do objeto psicológicos e em seus efeitos subjetivadores.
\end{abstract}

Palavras-chave: Foucault; Psicologia; saberes psis; corpo/alma; loucura.

\section{Psychology in Michel Foucault's História da Loucura}

\begin{abstract}
Michel Foucault investigates "the history of the relations that the thought keeps with the truth" and disnaturalizes body, soul and psique as historical and discursive inventions, which have meaning only if included into the epistemique arrangements productions of truths, in the case, the emergence of modern thought, specially about the human sciences, in general. This research studies the Foucault's order of the speech on Psychology, in his book História da Loucura,

^Este trabalho originou-se de uma parte do pós-doutorado em Filosofia de Fernando de Almeida Silveira, em 2008: Michel Foucault e a Constituição Histórica da Psicologia e do Sujeito Psicológico. Departamento de Filosofia e Metodologia das Ciências - UFSCar - São Carlos. Meus agradecimentos à FAPESP, pelo financiamento desse projeto de Pós-Doutorado e aos professores Richard Simanke e Étienne Bimbenet.

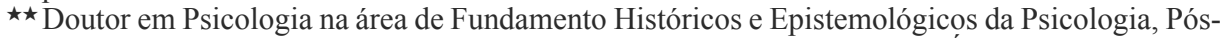
Doutor em Filosofia. Professor adjunto de Psicologia e Humanismo e de Ética da Universidade Federal de São Paulo. - Campus Baixada Santista. Avenida Almirante Saldanha da Gama, 88/89 - Ponta da Praia - Santos, SP - Brasil. CEP: 11030-400.

E-mail: fernando.silveira@unifesp.br

$\star \star \star$ Formado em Psicologia pela Universidade Federal do Rio Grande do Sul (UFRGS), Mestre em Filosofia e Metodologia das Ciências pela Universidade Federal de São Carlos (1992) e Doutor em Filosofia pela USP (1997). Professor Associado da Universidade Federal de São Carlos. E-mail:drts@power.ufscar.br
\end{abstract}


with the aim of providing allowances for understanding the history of the speeches of Psychology, about the building of psychological subject and object and its subjectivateurs effects.

Keywords: Foucault; Psychology; psis knowledge; body/soul; madness.

\section{INTRODUÇÃO}

Em um sentido amplo, Foucault estuda, através de uma arqueogenealogia dos saberes, "a história das relações que o pensamento mantém com a verdade" (ESCOBAR, 1984, p. 30). E desta maneira, como a correlação entre pensamento e verdade se estabelece na constituição de subjetividades locais, regionais e historicamente, conforme a seguir:

Através de quais jogos de verdade o homem se dá seu ser próprio a pensar quando se percebe como louco (A história da loucura), quando se olha como doente (O nascimento da clínica), quando reflete sobre si como ser vivo, ser falante e ser trabalhador (As Palavras e As Coisas), quando se julga e se pune enquanto criminoso (Vigiar e Punir)? Através de quais jogos de verdade o ser humano se reconheceu como homem de desejo (História da Sexualidade)? (ESCOBAR, 1984, p. 75).

Sob um viés específico, podemos reconhecer que, para Foucault, os "enunciados de verdades são raridades", na medida em que demandam um esforço de pensamento para que se alcance a sua expressão - a sua "dizibilidade" - a qual, freqüentemente, só é perceptível pelo pesquisador a partir de uma análise de amplos momentos históricos.

Por sua vez, vemos o estabelecimento de um jogo de pressuposição recíproca entre a raridade dos enunciados e a multiplicidade de sentidos deles advindo. Por exemplo, vemos pesar a reconhecível pluralidade de sentidos compreendida enquanto "pletora do significado em relação a um significante único" (FOUCAULT, 1969, p. 136) - que a enunciação de "corpo, alma ou psiqué" possa vir a comportar.

Aliás, pluralidade esta evidenciada pelas variadas "enunciações de verdades" sobre os corpos/almas estudadas por Foucault. Por exemplo: "corpos/almas disciplinados, excluídos, delinqüentes, enlouquecidos, patologizados", dentre outros.

Assim, "corpo, alma e psique", mais do que estruturas naturalizadas do sujeito de conhecimento, são elementos no exercício dos embates dos discursos, poderes e saberes, cartografados por Foucault em seus estudos arqueogenealógicos.

É neste contexto que Foucault abre espaço para os estudos da sua arqueologia, dedicada ao estudo das regras discursivas de formação do saber. Como também à sua genealogia, dedicada às relações constitutivas entre poder, saber e corpo, estava implicada a constituição histórica do sujeito. Com a primeira, Foucault investigou a posição e formação do sujeito do conhecimento através 
das regras discursivas do saber, com a segunda, sua posição e formação através das práticas sociais. Nesse sentido, em que pese certa dose de retrospectivismo, Foucault é coerente quando diz que, antes de tudo foi o sujeito, e não o poder, o tema geral de suas pesquisas (DEFERT; EWALD, 1994, p. 223).

No entanto, é importante frisar, preliminarmente, que a análise das formações, regularidades, rarefações e disposições discursivas, investigadas por Foucault em sua fase arqueológica (também denominada pelo autor em $\mathrm{A}$ Ordem do Discurso, de fase crítica) não se separa bipolarmente da sua analítica das relações de poder, saber e corpo, inerentes aos estudos da sua fase genealógica.

É o que veremos no texto em questão, em seu efeito de conjunto, na medida em que se, a princípio, História da Loucura é obra na qual Foucault nos apresenta, primordialmente, as reconfigurações discursivo-arqueológicos dos dizeres da loucura, desde o Renascimento até a Modernidade, por sua vez, é diagnosticável, simultaneamente, os deslocamentos de poder e os mecanismos de controle emergentes de tais produções discursivas, seja no sentido do exílio dos loucos no Renascimento, através da nau dos Loucos que navegavam pelos rios da Europa; seja no sentido da constituição de poder sobre os loucos internados enquanto desatinados no Classicismo; seja nos nítidos exercícios de poder-saber que os discursos do louco enquanto doente mental propiciarão, através dos dizeres científicas mais heterogêneos, como os de Pinel, Freud e dos juristas e psicólogos forenses, na constituição do sujeito apenável.

O que temos, portanto, é um contexto prático-discursivo da loucura no qual discursos e poderes-saberes, na edificação dos dizeres sobre nossos corpos-almas enquanto elementos de seus embates e exercícios, se remetem mutuamente.

Isto se deve ao fato que os dispositivos de controle e de exercício de poder, relevados em sua genealogia, podem emergir das formações e enunciados discursivos, como também no sentido reverso. Nas palavras de Foucault, "entre o empreendimento crítico [arqueológico] e o empreendimento genealógico, a diferença não é tanto de objeto ou de domínio mas, sim, de ponto de ataque, de perspectiva e de delimitação" (FOUCAULT, 1996[1970], p. 66-67). Ou seja, não há bipolaridade ou separatividade entre arqueologia e genealogia em Foucault mas sim imbricações entre discursos e as relações de poder/saber deles inerentes.

É o que Foucault (1996[1970], p. 69-70) nos esclarece no belo trecho de sua aula inaugural, no Collège de France:

As descrições críticas [arqueológicas] e as descrições genealógicas devem alternar-se, apoiar-se umas nas outras e complementarem. A parte crítica da análise liga-se aos sistemas de recobrimento do discurso; procura detectar, destacar estes princípios de ordenamento, de exclusão, de rarefação do discurso. Digamos, jogando com as palavras, que ela pratica uma desenvoltura aplicada. A parte genealógica da análise detém, em contrapartida, nas séries de formação efetiva do discurso: procura apreendê- 
lo em seu poder de afirmação, e por aí entendo não um poder que se oporia ao poder de negar, mas o poder de constituir domínios de objetos, a propósito dos quais se poderia afirmar ou negar proposições verdadeiras ou falsas. Chamemos de positividades desses domínios de objetos; e, digamos, para jogar uma segunda vez com as palavras, que se o estilo crítico é o da desenvoltura estudiosa, o humor genealógico será o de um positivismo feliz.

Assim reconhecendo que, a pretexto de estudar a arqueologia dos discursos da loucura em Foucault, também podemos diagnosticar as tensas relações de poder e saber que dele emergem.

E devido à importância da Psicologia em Foucault, esta pesquisa estuda a ordem do discurso foucaultiano sobre os saberes psicológicos e seus "conceitoschave" - corpo, alma moderna e psiqué - tendo como destaque a Psicologia nos seus textos, avaliando em que medida a noção de psiqué em Foucault situaria a Psicologia enquanto espaço social crítico (no entrelaçamento entre percepção, normalização, resistência e constituição histórica do sujeito), na produção histórica e perceptual do sujeito psicológico.

Esta pesquisa é aprofundamento de nosso trabalho sobre o corpo e a alma na genealogia de Michel Foucault (Mestrado: Michel Foucault e a Constituição do Corpo e da Alma do Sujeito Moderno), os quais culminaram em uma tese de Doutorado (Corpos Sonhados-Vividos: A Questão do Corpo em Foucault e Merleau-Ponty) na qual se analisou a correlação entre a concepção de corpo, interpenetrado de história, na genealogia foucaultiana (principalmente em Vigiar e Punir e História da Sexualidade - vol. 1 - A Vontade de Saber) e o corpo próprio: elemento fundante da experiência perceptiva, principalmente no livro Fenomenologia da Percepção de Merleau-Ponty.

Este artigo é parte do projeto de Pós-Doutorado (em andamento desde fevereiro de 2007 e finalizado em abril de 2008), que é uma reavaliação dessas pesquisas, a partir de nova perspectiva. No caso, trata-se de focalizar nossa leitura da Psicologia em Foucault a partir da evolução do conceito de Psicologia na fase arqueológica.

No artigo em questão, estudaremos a noção de Psicologia a partir da leitura do seu livro História da Loucura, na qual estudava o primado dos discursos da loucura sobre as práticas sociais que a constitui historicamente e, portanto, situado em sua fase arqueológica.

\section{A Loucura no Renascimento}

No seu livro História da Loucura (1997[1961]), Foucault investiga as condições de possibilidade e de existência da psicologia, desde a Idade Média até os tempos modernos, enquanto saber que se constitui em torno da constituição do sujeito louco e de todas as suas figuras, Ao analisar a hipotética existência da psicologia, desde o fim da Idade Média e em todo o transcurso da 
Renascença, compreende que o saber psicológico é impensável nestes períodos históricos, seja enquanto ciência como a conhecemos, seja no que se refere à loucura enquanto doença mental.

No fim da Idade Média e na Renascença, a loucura é uma expressividade do sujeito envolta em mistério, muitas vezes associada a forças místicas de uma radiância sobrenatural, na qual o louco se apresenta como o revelador das contradições e hipocrisias sociais e na qual, mesmo expulso das cidades em naves que deslizavam pelos rios da Renânia e nos canais flamengos, ainda reside nessa expressividade, singularidades e descontinuidades que impediriam a plena objetivação de seus discursos e a definição precisa de seus sujeitos, de acordo com parâmetros de uma medicina ainda bem rudimentar, do ponto de vista científico e que a ele ainda não se remetia, nos moldes da Modernidade.

O que se tinha, nesta fase, é a loucura, imersa nos jogos de semelhanças entre o micro e o macrocosmo da Renascença, como espelho da experiência trágica da pequenez do homem diante da infinitude do universo, em sua proximidade constante com a morte. É o que ilustram os quadros de Bosch, de Brueghel, de Thierry Bouts e Dûrer ao mostrarem, não só a loucura mas a própria realidade do mundo, absorvida no universo de imagens fantásticas, atravessado pela ameaça da fome, da tentação, da fatalidade e das guerras.

Por sua vez, a esta experiência trágica da loucura do mundo foi se contrapondo, no humanismo da Renascença, no transcurso do século XVI, principalmente em Brant, Erasmo e Calvino, uma loucura advinda da razão, submetida a uma reflexão crítica que a despia de suas alegorias metafísicas e transcendentais. Em decorrência, à origem cósmica da loucura foi se erguendo uma prática discursiva que considerava que a loucura "nasce no coração dos homens [na medida em que ele] organiza e desorganiza sua conduta" (FOUCAULT, 1997[1961], p. 28), não como efeito de um mistério ocultado mas fruto da prática moral do homem, no desvio do indivíduo do caminho da retidão.

Ou seja, loucura considerada enquanto "forma relativa à razão" enquanto medida própria do homem correto, de maneira que "toda loucura tenha sua razão que a julga e controla, e toda razão sua loucura na qual ela encontra sua verdade irrisória” (FOUCAULT, 1997[1961], p. 30).

Neste sentido, Erasmo aborda a loucura enquanto imanência da razão, ou seja, não como radiância mítica e reveladora mas enquanto imagem do castigo do homem que erra e, portanto, que se expõe aos efeitos da própria inverdade delirante dos seus atos.

A partir deste enfoque, segundo Foucault, tem-se a dissipação da origem sobrenatural da loucura e a sua amarração "no meio das coisas e das pessoas. Retida e segura. Não existe mais a barca, porém o hospital" (FOUCAULT, 1997[1961], p. 42).

Este discurso da loucura, enquanto expressão da estreiteza de discernimento do homem desvairado em sua mesquinharia mundana, é que possibilita o surgimento da experiência clássica da loucura. 
Por outro lado, se a experiência trágica da lepra, durante a Idade Média, devastava, juntamente com as pestes e as guerras, as comunidades e ameaçava os indivíduos, material e espiritualmente. Com o desaparecimento dela, no decorrer do século XVI, um novo mal se instala no imaginário e nos corpos das pessoas: a doença venérea, compreendida como sinal da punição divina aos pecadores e libertinos.

No entanto, é somente no século XVII que a doença venérea, influenciada pelos princípios do internamento é que vai, ao lado da loucura, começar a ser submetida aos preceitos do discurso médico que, com o suceder de alguns séculos, como veremos, irá torná-la objeto definido de patologização e de psicologização.

\section{A Loucura no Classicismo}

O que está em jogo são as renovadas práticas discursivas da internação enquanto invenção institucional do século XVII e XVIII, com o surgimento de várias casas de internamento. A partir de então, o internamento veio ocupar, durante o Classicismo, o vazio deixado pela segregação dos leprosos, de forma que, em menos de meio século, em Paris, um em cada cem habitantes estava internado.

Os internamentos eram efetuados sob as mais diversas formas: através de cartas régias, de encaminhamentos policiais, de solicitações de familiares ou por pedido dos curas paroquiais. A multiplicidade de critérios e de apelos para internação gerava uma fauna heterogênea de internados, podendo ser eles, por exemplo: pobres, desempregados, criminosos, prisioneiros políticos, prostitutas, usurários, sodomitas, crianças órfãs, mulheres viúvas, ateus, vagabundos, epilépticos, senis, alquimistas, blasfemadores, sacrílegos, regicidas. Dentre eles, apenas dez por cento eram internados por insanidade. De tal maneira que o internamento se configurava mais como um dispositivo de exercício de poder, através do isolamento dos excluídos sociais do que enquanto medida na diferenciação dos diversos tipos de subjetividades e na constituição diferenciada da categoria médica do louco.

O que temos é o surgimento de uma nova sensibilidade social, com o banimento da loucura da sua liberdade imaginária renascentista.

Aliás, Foucault considera que foi no Classicismo que uma nova percepção da loucura enquanto risco para a sociedade começou a se delinear, sendo referenciada enquanto fator de "desorganização da família, desordem social, perigo para o Estado" (FOUCAULT, 1997[1961], p. 80).

O que se tem é um processo de vivência de uma experiência social de reinvenção da loucura para, com o passar de alguns séculos, gradativamente ocorrer a edificação do seu conhecimento científico. Ou seja, o saber da loucura não se apresenta, na história do conhecimento, como verdade já dotada, de início, do seu aparato psicológico.

Assim, como efeito mais direto da segregação do louco via internamento, o que se tem é, principalmente a invenção social da alienação através do isolamento dos excluídos em ambiente estranho, não familiar, portanto, alienante. 
Com isto, muito além do papel negativo de exclusão, inerente à prática do internamento, o que se tem é um papel positivo de organização, a partir de toda uma reconfiguração de uma ética, de "novas linhas de divisão entre o bem e o mal, o reconhecido e o condenado, e o estabelecimento de novas normas na integração social" (FOUCAULT, 1997[1961], p. 83).

Dentre estes limites, o sexo vai servir como limiar de separação e de cristalização da identidade alienada das mulheres "libertinas", das prostitutas, dos devassos, dos indivíduos com doenças venéreas e dos sodomitas, por exemplo.

Neste sentido, o internamento é castigo e terapia na purificação das almas e na cura dos corpos. Portanto, remédio moral mais do que ciência psicológica, na condenação de uma conduta desregrada mas não classificada como patologia. Em decorrência, há a invenção de novos patamares éticos do que seja sexualidade, amor, sagrado e profano.

No entanto, justamente a partir desta experiência do internamento, estes comportamentos, antes dispersos na rede das relações sociais foram deslocados do campo da experiência cotidiana para serem integrados no campo do desatino enquanto desajustes, não só morais mas patologizáveis.

Como? Esta patologização da conduta louca se produz a partir desta correlação da loucura aos discursos dos desatinos, de forma a permitir a complexa transmutação - prática e epistêmica - da já apresentada radiância singular e quase sobrenatural da loucura no Renascimento em comportamento desatinado no período clássico, o qual passará a ser discursivamente reconhecido como revestido de falha, erro ou descompasso do discernimento do sujeito do que seja moral e socialmente adequado.

Desta maneira, no Classicismo, a loucura enquanto erro e falta é remetida aos questionamentos éticos das proibições sexuais, dos interditos religiosos, das liberdades do pensamento e do coração formando "uma experiência moral do desatino que serve, no fundo, de solo para nosso conhecimento 'científico' da doença mental" (FOUCAULT, 1997[1961], p. 107), alavancada pela prática discursiva e social do internamento, a partir do qual se erguerá, futuramente, as bases dos saberes psiquiátricos e psicológicos.

De forma que a formação discursiva, produtora da conduta do desatinado, abrirá espaço para os estudos destes comportamentos, não apenas do ponto de vista ético-moral mas enquanto anomalia psicológica.

Porém, é importante ressaltar que a emergência da loucura como doença mental se produz, gradativa e intensamente através de macromomentos históricos, no transcurso do Classicismo para a Modernidade, conforme abordaremos detidamente até o fim deste artigo. 
No entanto, Foucault destaca que a história da loucura não se restringe à sua relação com o domínio exclusivo do conhecimento médico, paramédico ou psicológico. A delimitação da loucura como doença mental, no contexto da medicina, se relaciona à experiência jurídica da alienação, na constituição do estatuto do que seja um indivíduo incapaz, perturbador do grupo, de acordo com os preceitos morais, éticos e políticos dos séculos XVII e XVIII.

Assim, se antes desta fase, o internamento ocorria pela solicitação da família, do cura da paróquia, do tenente de polícia ou do rei, sem laudo pericial médico, Foucault demarca que seria a partir do momento em que a jurisprudência da alienação do século XVII se torna preliminar a todo internamento, é que teríamos a inserção do papel do médico na verificação da incapacidade do indivíduo potencialmente internável, no processo de convencimento do magistrado.

Neste contexto é que se tem a emergência das estruturas rudimentares de uma psicopatologia ou de uma psicologia das debilidades mentais, na criação das figuras dos estúpidos, imbecis, parvos, idiotas enquanto escala psicológica para a determinação do juiz, ao considerá-los inofensivos ou perigosos, internáveis ou não.

O que está em jogo, para Foucault, é a desnaturalização do homo natura ou de um homem normal "considerado como dado anterior a toda experiência da doença" (FOUCAULT, 1997[1961], p. 132). Nas suas palavras, "se é preciso situá-lo, não é num espaço natural, mas num sistema que identifique o socius ao sujeito de direito" (FOUCAULT, 1997[1961], p. 132).

É assim que se inventa, nos séculos XVII e XVIII, a figura e o conceito do alienado psicológico, na imbricação entrecruzada entre Psicologia, Psiquiatria e Direito.

Assim sendo, no internamento, segundo Foucault, o que se tem é a loucura associada à noção de desatino, o qual já implica numa escolha ética do indivíduo pelo comportamento errante e desregrado, já que a razão, como vimos, antecede à loucura. Ou seja, a conduta originariamente fundante do comportamento alienado não é inocente, já aponta para o desvio do caráter do sujeito que a realiza.

Nas palavras de Foucault, se durante a Idade Média e a Renascença "a loucura estivera ligada ao Mal, mas sob a forma de transcendências imaginárias; doravante, ela se comunica com ele pelas vias mais secretas das escolhas individuais e das más intenções" (FOUCAULT, 1997[1961], p. 137).

Ou seja, o que se tem é a loucura atrelada a uma ética social que exige que o indivíduo louco seja preliminarmente consciente de seus desatinos, enquanto posicionamento existencial do indivíduo na escolha de uma vida errática.

Neste sentido, a loucura clássica não é uma doença mas "o extremo dos defeitos" (FOUCAULT, 1997[1961], p. 136). Por exemplo, foram internados indivíduos considerados: "grande mentiroso", "pregador de cartazes", 
"espírito inquieto, triste e ríspido", "homem que passa os dias e as noites a atordoar os outros com suas canções e a proferir as blasfêmias mais horríveis" (FOUCAULT, 1997[1961], p. 135).

Sob as implicações psicológicas de tal arranjo de verdades, segundo Foucault, "tudo se passou como se a explicação psicológica duplicasse a incriminação moral, quando há muito tempo nos acostumamos a estabelecer entre elas uma relação de subtração" (FOUCAULT, 1997[1961], p. 139).

De tal maneira que somente quando os sistemas de saberes do Classicismo puderem romper com esta relação siamesa entre moral e verdade psicológica, é que será possível a emergência de discursos que nos levariam ao esboço de um campo de ciência psicológica, mesmo que incipiente.

É neste contexto que vemos um exemplo no qual, conforme apresentamos na introdução deste artigo, os deslocamentos discursivos da loucura propriamente ditos propiciam, no seu bojo, toda uma reconfiguração de novos campos de saberes e poderes, conforme apontaremos nas páginas seguintes, ao investigarmos os deslocamentos discursivos e, imbricadamente, de saberes-poderes, na constituição dos corpos-almas loucos, do Classicismo à Modernidade.

De início, estudemos os rearranjos em questão no Classicismo.

\subsection{Corpos, Almas e loucura no Classicismo}

A esta instabilidade epistêmica na qual a constituição do saber sobre as figuras da alma do louco se vê imerso, Foucault denominou de "penumbra conceitual" (FOUCAULT, 1997[1961], p. 200), na qual a almejada objetividade dos discursos da loucura se vê comprometida pelo imaginário ético da sociedade, a qual afeta a própria sensibilidade do médico, ao estipular determinada nosografia.

Neste sentido, o que está em jogo, na constituição do objeto clássico da loucura, não seria apenas a precisão inatingida de suas taxinomias mas sim o desenvolvimento de uma apreensão do que seja o indivíduo louco, em sua sintomatologia e comportamento, a partir da relação terapêutica que se estabelece entre o doente, detentor do mal, com o médico, detentor do discurso e do poder de curar.

Seria neste âmbito de correlação clínica que se ergueria para Foucault, o confronto "entre o médico e o doente no mundo imaginário da terapêutica" (FOUCAULT, 1997[1961], p. 208), no processo de construção de uma loucura historicamente situada, atravessada pelos valores morais do desatino.

Desta forma, seria a partir da experiência inerente a este referido espaço terapêutico que veríamos a sedimentação dos discursos da experiência clínica do médico em conhecimento da loucura, em um processo de purificação conceitual que viria, paulatinamente, permitir a superação dos pré-conceitos do desatino na direção da edificação da doença mental, objetivamente determinável.

O que estaria em jogo nos discursos emergentes deste espaço terapêutico? 
A princípio, veríamos emergir certa forma de dizibilidade sobre as verdades dos corpos e das almas. Desta maneira, o fenômeno discursivo da loucura se abriria à análise de campo epistêmico preliminar, que diga respeito à maneira como se abordar as questões dos corpos e das almas na sua correlação com a loucura.

Neste sentido, seria a loucura, fenômeno eminentemente corpóreo ou anímico?

Tal indagação seria a frente da articulação dos dizeres tanto dos psiquiatras espiritualistas ou materialistas, em um processo de produção de discursos no qual, em vários momentos, se tende a um reducionismo da loucura, seja a uma realidade eminentemente da alma ou, então, do corpo.

Assim sendo, seria a loucura afecção orgânica de um princípio material? Ou perturbação espiritual de uma alma imaterial?

Para Foucault, além desta dualidade, o que está em questão é uma problemática na qual “corpo e alma estão juntos” (FOUCAULT, 1997[1961], p. 214).

Neste contexto, em vários autores, como Voltaire, a loucura é "doença dos órgãos do cérebro" (FOUCAULT, 1997[1961], p. 209), no sentido de resguardar a alma, salva por Deus, na medida em que não a torna comprometida pela loucura, pois esta é relacionada aos distúrbios do organismo, que impedem a percepção superior dela.

O que está em jogo é a irredutibilidade da alma às vicissitudes do corpo, suas doenças e disfunções. Ou seja, mesmo a alma sendo influenciada pelas lesões do corpo, sua origem divina a resguarda de submetê-la totalmente às determinações da materialidade do corpo. Por sua vez, outros autores irão suplantar tais questões metafísicas e simplesmente se debruçarem sobre a imbricação do corpo e da alma na constituição da loucura, do ponto de vista exclusivamente fenomênico e não propriamente filosófico, neste caso, mais próximo dos estudos de Voltaire.

É assim que surgem três âmbitos estruturais da loucura. O primeiro deles, exterior, diz respeito às relações de causalidade influenciadora da conduta do louco. É o caso de Willis que, ao analisar a loucura como alteração dos espíritos animais, irá verificar, dentre suas causas imediatas, "a alteração mecânica que incide simultaneamente sobre a força do movimento e sobre sua trajetória" (FOUCAULT, 1997[1961], p. 215), por exemplo, fenômenos físicos que gerariam agitações dos espíritos animais, na produção da violência do comportamento maníaco. Ou alterações químicas que irão afetar materialmente a conduta do sujeito na produção do comportamento irregular, através, por exemplo, da acidificação dos espíritos animais (FOUCAULT, 1997[1961], p. 215).

Assim, eventos exteriores ao sujeito repercutiriam, mecanicamente, na produção da causalidade que trará à tona, a conduta desequilibrada.

$\mathrm{Na}$ mesma linha, os efeitos fisiológicos do ressecamento ou amolecimento das fibras nervosas é o que induziria, do ponto de vista orgânico, ao surgimento de um sintoma de uma alma louca, segundo os estudos de Sydenham sobre a 
patologia das fibras nervosas (FOUCAULT, 1997[1961], p. 217). Por exemplo, é o caso do enrijecimento e da secura delas, influenciando o comportamento maníaco, ou de sua frouxidão e umidade, encontrado no cérebro do melancólico.

No geral, segundo Foucault, o que se tem é uma "comunicação qualitativa imediata" entre corpo enquanto "coisa modificada" e alma enquanto "qualidade alterada" (FOUCAULT, 1997[1961], p. 217), na constituição de uma determinada percepção organizada da loucura.

Assim, o que está em jogo é a verificação de "estruturas lineares e perceptivas" (FOUCAULT, 1997[1961], p. 218) na produção do comportamento alterado da loucura, em uma correlação na qual a estrutura anatômica do cérebro, ou determinado rearranjo bioquímico do corpo, são centrais na apreensão da percepção equivocada pela alma.

Por sua vez, além desta causalidade imediata, um conjunto disperso de causas distantes poderia afetar o comportamento do indivíduo. Por exemplo, "as paixões da alma, as meditações profundas, a cólera, a tristeza, o temor, os pesares longos e pungentes, o amor desprezado, [ou] ar muito quente, muito frio ou muito úmido, [ou] o amor pelas ciências e a cultura das letras [...], o aumento do luxo. [Ou ainda] a leitura de romances, os espetáculos de teatro, tudo o que aguça a imaginação" (FOUCAULT, 1997[1961], p. 222), afetariam determinada organização dos corpos e das almas, em suas manifestações psicológicas. Como também a lua, as marés, as bebidas alcoólicas, o vírus da sífilis, vermes, hereditariedade, o onanismo, o ciúme, a alegria excessiva, dentre outros (FOUCAULT, 1997[1961], p. 223-224).

Neste contexto, além das recém-descritas relações de causalidade, surgiria a paixão como segunda estrutura da loucura de maneira que, mais do que uma causa distante da loucura, ela surge como a "superfície de contato entre corpo e alma [enquanto] condição de possibilidade da loucura" (FOUCAULT, 1997[1961], p. 226) na produção desordenada dos movimentos do espírito, muito mais do que um mero fator causal de tal desequilíbrio.

Isto se deve ao fato das paixões alterarem os humores, provocarem agitações e promoverem predisposições perturbadoras dos corpos, na afetação da alma, então insensata.

Por outro lado, a persistência de tais agitações das paixões pode promover o surgimento de comportamentos alucinados e delirantes enquanto terceira estrutura da loucura, rompendo com a linearidade entre os movimentos exteriores dos corpos na produção das idéias. Com isto, o que se provoca é a perda da adaptabilidade à realidade como, por exemplo, no caso da fixação do melancólico a uma idéia delirante; de um convulsivo, que se arrebata descontroladamente por lembranças.

A partir do reconhecimento destas três estruturas da loucura, vale lembrar, agora, a bela passagem sintética na qual Foucault (1997[1961], p. 232) apresenta a dinâmica da manifestação da loucura: 
Na loucura, a totalidade alma-corpo se fragmenta: não segundo os elementos que a constituem metafisicamente, mas segundo figuras que envolvem, numa espécie de unidade irrisória, segmentos do corpo e idéias da alma. Fragmentos que isolam o homem de si mesmo, mas sobretudo que o isolam da realidade; fragmentos que, ao se destacarem, formam a unidade irreal de um fantasma, e em virtude dessa autonomia o impõem à verdade. [...] Em outras palavras, começando com a paixão, a loucura não passa de um movimento vivo na unidade racional da alma e do corpo; é o nível do desatino; mas esse movimento logo escapa à razão da mecânica e, em suas violências, em seus estupores, em suas propagações insensatas, torna-se um movimento irracional; é então que, escapando ao peso da verdade e a suas coações, liberta-se o Irreal.

Ou seja, a loucura é fragmentação da articulação corpo-alma, afetada pelas paixões descontroladas, no desequilíbrio das causalidades mecânicas, na construção da conduta irracional e de um campo de irrealidade.

\subsection{Figuras da Loucura no Classicismo}

Assim sendo, desde a demência, compreendida enquanto a manifestação mais típica da loucura em sua negatividade da razão: “desordem, decomposição do pensamento, erro, ilusão, não-razão e não-verdade" (FOUCAULT, 1997[1961], p.252), é que vemos a configuração de determinado arranjo epistêmico sobre o que seja a loucura, em sua relação com os corpos e almas, desde os séculos XVII e XVIII.

Em Willis, o que se vê é a definição de uma variedade de categorias a compor as bases dos discursos dos corpos e das almas. Haveria, neste contexto, a "alma racional", perturbada pela demência, que se encerra no corpo apenas pela existência de um elemento misto, que é a "alma sensitiva", "que veicula os poderes intermediários e mediadores da imaginação e da memória" (FOUCAULT, 1997[1961], p. 252), fornecendo impressões sensíveis na produção das emanações do espírito. Por sua vez, a "alma corporal" residiria no cérebro, no espaço orgânico e funcional, formada pelos espíritos animais.

Desta maneira, a demência é fruto de perturbação do cérebro e dos espíritos, ou de ambos.

Surgem, também, outras categorias, as quais nos interessam apenas enumerar: ao frenesi, compreendido enquanto febre aguda inflamatória, provocadora de inchaço, vermelhidão, insônia e hiper-sensibilidade aos ruídos (FOUCAULT, 1997[1961], p. 258), temos a comparação com a besteira, patetice ou idiotia, que é a demência que aparece na infância; a imbecilidade, que é a demência que surge ou se estende na vida adulta; o disparate ou condição infantil, quando a demência aparece na velhice (FOUCAULT, 1997[1961], p. 258). 
Por sua vez, a estupidez se distingue das categorias da demência, pois esta é uma perturbação do juízo, enquanto aquela é uma deficiência da sensação, que impede a compreensão da realidade e a organização da sensação em percepção (FOUCAULT, 1997[1961], p. 261).

Enquanto isto, a melancolia surge, desde o século XVI, como fixação do indivíduo a idéias delirantes, por exemplo, "acreditam serem animais", "que são vasilhas de vidro", "culpados de algum crime" (FOUCAULT, 1997[1961], p. 262) o que, no entanto, não os impedem de serem sensatos a respeito da realidade, já que o seu delírio é focal e isolado. E a mania a ela se remete enquanto delírio, no entanto, tem um caráter mais fantasioso e quimérico, podendo ser violento na constituição de sua irrealidade. Em ambos os casos, o que se tem são perturbações dos espíritos animais, no primeiro caso, por excesso de humor úmido, pesado e frio e no segundo, por esgotamento e rigidez deles (FOUCAULT, 1997[1961], p. 272).

Há ainda que se ressaltar que a histeria não fora sempre tratada como loucura, mas sim como convulsões e espasmos (FOUCAULT, 1997[1961], p. 277), típicos das mulheres, devido à "má influência do útero" (FOUCAULT, 1997[1961], p. 278), cuja causa era desconhecida e a terapêutica, incerta, no século XVIII. Da mesma maneira, a hipocondria era considerada como "alucinações que caminham apenas sobre a saúde” (FOUCAULT, 1997[1961], p. 277) e não, demência.

No entanto, foi apenas a partir do século XVII que o mito de que a histeria se devia ao deslocamento do útero pelo interior do corpo, já que se compreendia que ele "sobe ao fígado, baço, diafragma, estômago, peito, coração, pulmão, faringe e cabeça" (FOUCAULT, 1997[1961], p. 283), foi ultrapassado pela concepção de Le Pois, que considerava que a histeria se deve, não ao referido deslocamento, mas à "difusão dos humores pelos nervos", na medida em que os espíritos animais podem penetrar, desordenadamente, pelo organismo, alterando a percepção do sujeito e a compreensão da alma, principalmente nas mulheres, cuja fragilidade física as tornaria mais suscetíveis aos efeitos destes ímpetos.

É neste ponto que nos interessa situar importante questão: seria a partir do surgimento dos discursos do indivíduo afetado pelos "males dos nervos", a partir dos estudos da histeria, que haveria a superação da noção de desatino, enquanto efeito da falta moral do sujeito que se desencaminha na vida, para uma análise baseada na verificação do grau de sensibilidade do sujeito submetido às alterações dos humores, variável de indivíduo para indivíduo e, em linhas gerais, distinguível conforme o sexo da pessoa.

Estamos, assim, diante da gênese da noção de sensibilidade, "que não é sensação", já que esta se afere a um sistema de causalidade constantemente linear e objetivável das relações mecânicas entre o funcionamento do corpo e suas influências perante as emanações da alma; para o âmbito de uma compreensão da percepção subjetiva de cada indivíduo diante deste referido funcionamento dos corpos e das almas. 
Assim sendo, se antes as alterações sensoriais se deviam à exposição do sujeito às conseqüências psico-físicas de sua conduta anti-ética ou imoral, agora o campo epistêmico se abre para uma enunciação de uma sensibilidade exacerbada, fruto dos apelos do mundo perante determinada configuração hiper-sensível de certos corpos e almas.

Distancia-se, com isto, da pressuposição de que os efeitos psicológicos da loucura, conforme dissemos, têm sua origem em uma falta moral, já que os atos do sujeito não são diretamente responsáveis por determinada configuração estrutural da sua percepção. É o que se tem no exemplo de que a mulher não é culpável por ter um corpo feminino mais exposto às oscilações dos humores, na manifestação da histeria, já que possui suas fibras mais frágeis.

Desta forma, a experiência imoral ou amoral do desatino se vê comprometida. Nas palavras de Foucault, "o que era cegueira vai tornar-se inconsciência, o erro se tornará falta” (FOUCAULT, 1997[1961], p. 295), em virtude do efeito determinador de uma sensibilidade mais débil ou mais frágil.

É este novo jogo de verdades que permitirá a emergência de uma reconfiguração de discursos que propiciará a emergência de uma psiquiatria científica e de uma psicologia, a partir do século XIX, em suas aproximações e distanciamentos das explicações morais das condutas, sensatas ou loucas, agora rearticuladas a partir da noção de doenças dos nervos e de suas decorrentes sensibilidades, a serem estudadas, categorizadas e freqüentemente individualizadas, na análise clínica de cada caso, pelos detentores dos saberes psi.

E em que pese a existência de uma miríade de tratamentos terapêuticos para as várias categorias de loucura - por exemplo, utilização de ervas; de partes do corpo (cabelos, urina, leite de mulher, pó de crânio); cauterizações, transfusão sangüínea, imersão em água, banhos e duchas, caminhadas, passeios a cavalo, máquinas giratórias, músicas, teatralizações, terapia pelo trabalho.

Para Foucault, o que se verifica é a inexistência de condições, não só práticas mas epistêmicas, da possibilidade de existência da Psicologia no Classicismo. Isto ocorre pois havia uma justaposição entre físico e psicológico, ou seja, inexistia tratamento psicológico propriamente dito. É o que demonstra ao citar que, quando se tratava um indivíduo louco com um chá amargo ou como uma terapêutica pelo trabalho, tratava-se tanto o corpo como a alma. Assim, teríamos a indistinção entre medicamentos físicos, psicológicos ou morais (FOUCAULT, 1997[1961], p. 325).

Por outro lado, só surgirá a psicologia no momento histórico no qual se estabelecer a tripla diferença entre tratamento físico, moral e psicológico.

Isto só ocorrerá quando, no século XIX, “a problemática da loucura se deslocou para uma interrogação do sujeito responsável” (FOUCAULT, 1997[1961], p. 325), de maneira que o espaço moral da culpabilidade do sujeito dará os limites distintivos entre o que seja psicológico, principalmente a partir da utilização dos laudos periciais no convencimento do juiz, os quais determinarão a imputabilida- 
de ou não do sujeito transgressor da norma social. E mais do que isto, apenável e punível. Desta forma, quanto à psicologia, serão destinados os comportamentos organizados “ao redor da punição” (FOUCAULT, 1997[1961], p. 325).

Neste contexto, ao campo da cura física será referida a conduta do "determinismo inocente"; na medicina das causalidades orgânicas da doença; no que se refere à terapêutica moral, "a liberdade falível" (FOUCAULT, 1997[1961], p. 325), na ocorrência de condutas que infringem os valores sociais mas não consideradas puníveis pela lei.

\section{Loucura e Saberes Psis na Modernidade}

Sob outro prisma, no período antecedente à Revolução Francesa, já se verificava a individualização da loucura, a partir da limitação e redução do internamento, no sentido de liberar os internados referentes à imoralidade, a conflito familiar e à libertinagem leve. No entanto, os loucos eram explicitamente mantidos enclausurados e, em geral, acorrentados.

Por sua vez, com a "Declaração dos Direitos do Homem", promulgada pela Assembléia Nacional Constituinte da França revolucionária em 26 de agosto de 1789, em sua prerrogativa de não deter ninguém a não ser nos casos da lei, encerra-se a fase do internamento. Porém, os loucos serão mantidos mediante averiguação de juiz e mediante laudo médico que ateste a referida loucura.

Assim, ao redor das medidas judiciárias que irão reconhecer a identidade e a manutenção do louco no internamento, como também em comparação aos demais enclausurados ou enclausuráveis, quem é criminoso ou não criminoso e, através dos laudos periciais, imputável ou não imputável, é que se vai verificar a emergência de três estruturas prático-discursivas: a internação do louco, a objetivação da loucura e a loucura confrontada com o crime.

A partir de então, é que surge uma psiquiatria positiva de análise e identificação da loucura, através do seu reconhecimento objetivo e médico.

Por sua vez, surge a proposição de um internamento não como restrição absoluta da liberdade mas a partir de uma liberdade organizada, na administração de uma terapêutica para a sua recuperação.

Neste sentido, esta forma de aprisionamento terapêutico permite que surja "uma loucura despojada de todas as reações secundárias - violência, raiva, furor, desespero" (FOUCAULT, 1997[1961], p. 432), que transforma a animalidade predatória do desatino em uma "animalidade suave" (FOUCAULT, 1997[1961], p. 432), domesticada e suscetível, se não de plena recuperação, pelo menos de maior controle social do louco.

Foucault reconhece nesta recontextualização da loucura, que a coação do internamento, pela primeira vez, é configurada como espaço para afloramento "das formas essenciais de sua verdade" (FOUCAULT, 1997[1961], p.432), a partir da emergência de um espaço clínico, terapêutico e de psicologização, mesmo que incipiente, da loucura, pela primeira vez, como a conhecemos modernamente. 
Por sua vez, esta comparação entre crime e loucura provoca a emergência de uma escala de valores e gravidades a partir da qual se relativiza a noção hedionda de crime e faz surgir a figura da conduta escandalosa enquanto comportamento desatinado o qual, por sua vez, nem sempre será correlacionado a um caso extremo de loucura.

Neste sentido, o sujeito viciado, promíscuo, desregrado enquanto figura que ameaça à imagem tradicional da família burguesa, será desvelado do seu destino de ocultamento no interior das famílias e surgirá como objeto privilegiado de estudo da emergente ciência psicológica.

De tal forma que a análise psicológica da imoralidade da conduta escandalosa tem duas funções: permite "a adequação imediata à falta [inerente à referida conduta] e como meio de impedi-la antes que assuma uma forma criminosa" (FOUCAULT, 1997[1961], p. 444).

Neste contexto, Foucault estranha que a psicologia tenha surgido não de um aprimoramento da justiça mas como "exigência suplementar da moral, de uma espécie de estatização dos costumes e de uma espécie de depuração das formas da indignação" (FOUCAULT, 1997[1961], p. 445).

Ora, esta psicologia vai revelar o segredo do escândalo ocultado, através de uma evocação da consciência pública como medida para o julgamento da moral dos homens. É desta maneira que Foucault admite que "a interioridade psicológica foi constituída a partir da exterioridade da consciência escandalizada" (FOUCAULT, 1997[1961], p.445), na constituição de uma psicologia como fruto da moral cotidiana e burguesa.

Portanto, "conhecer o encadeamento das hereditariedades, do passado e das motivações só se tornou possível no dia em que a falta e o crime, deixando de ter apenas valores autóctones e de estar em relação apenas consigo mesmos, tomaram toda a sua significação de empréstimo ao olhar universal da consciência burguesa" (FOUCAULT, 1997[1961], p. 446).

Esta origem das formas psicológicas na consciência pública escandalizada é que servirá como suporte para o convencimento do juiz, nos casos em que loucura, desatino, insensatez, libertinagem e crime sejam condutas potencialmente visíveis na constituição dos discursos judiciários.

Neste sentido, por exemplo, a circunscrição da manifestação da loucura enquanto "verdade cotidiana da paixão, da violência e do crime" (FOUCAULT, 1997[1961], p. 455) permitirá a constituição de um sujeito psicológico, não mais afeito ao mundo desarrazoado do desatino, mas inserindo tal conduta desequilibrada no interior de "um mundo não coerente de valores, e nos jogos de má consciência", o que muitas vezes, permitirá a absolvição do indivíduo que, ocasionalmente, seja afetado pela intempestividade eventual de um comportamento vil e apaixonado sem que, contudo, seja considerado louco. 
O que está em jogo é a edificação de uma “percepção moral” da loucura, de acordo com os jogos de verdades que o juiz, aliado ao detentor dos saberes psis, irá construir sobre os fatos. Neste processo de produção de sujeitos, a partir do século XIX, se "reconhecerá a boa e a má loucura - aquela cuja presença confusa é aceita às margens da razão, no jogo entre a moral e a má consciência, entre a responsabilidade e a inocência, e aquela sobre a qual se deixa cair o velho anátema e todo o peso da ofensa irreparável" (FOUCAULT, 1997[1961], p. 453), abrindo margem para renovados campos de identidade dela como, por exemplo, a loucura perversa do libertino; a loucura heróica do indivíduo que mata a mulher adúltera, movido por paixão; a loucura do vício, fruto da degenerescência moral, típica do criminoso nato.

Este é o processo de tipificação das condutas dos sujeitos considerados loucos, no processo de constituição histórica dos próprios saberes psicológicos, em articulação ao desenvolvimentos dos saberes jurídicos. E será, a partir desta tipificação do sujeito louco, que surgirão outras figuras derivadas, para o melhor exercício do Direito e da Psicologia como, por exemplo: o louco internável, curável, perdoável ou criminoso, de maneira que "a alienação será depositada como uma verdade secreta no âmago de todo conhecimento objetivo do homem" (FOUCAULT, 1997[1961], p. 457).

Neste sentido, justamente em função de uma abordagem epistêmica positivista da loucura, tem-se o despregamento da loucura da soberania dos discursos do desatino e seu assujeitamento às renovadas formas psicológicas, seja do internamento sem correntes, no caso de Pinel; seja ao domínio do médico analista, na psicanálise de Freud, a partir do fim do século XIX.

Em ambos os casos, a partir de uma concepção analítica da conduta do louco, o que se visa é o estabelecimento de referência de causalidade do comportamento louco, na edificação de parâmetros, pelo menos gerais e tipificadores de sua sintomatologia, bem como do tipo de terapêutica ou abordagem a ser empregada, seja na sua recuperação, ou pelo menos, na minimização dos seus efeitos morais nocivos, a partir dos referenciais burgueses da sociedade.

Desta maneira, o que se tem é o exercício de poder de novos arranjos discursivos que, a pretexto de liberarem o louco do seu aprisionamento físico, o utilizam como elemento de exercício da configuração de novos saberes psis, na constituição da figura do louco desarrazoado: invenção da Modernidade.

Nas palavras de Foucault, desde o final do século XVIII, o que se trata, no âmbito da loucura, não diz respeito a uma "liberação dos loucos" mas sim de uma “objetivação do conceito de liberdade" (FOUCAULT, 1997[1961], p. 508), em sua fixação ao internamento ou à positividade dos saberes e tratamentos psis.

De tal forma que se, em outros períodos, a loucura se reportava ao não-ser do homem, no esquecimento de sua condição, contaminada pela animalidade do desatino ou pela radiância sobrenatural e desequilibradora de sua singular expressão, com o advento dessas novas formas psicológicas, em sua inter-relação com os saberes jurídicos, o que se tem é, doravante, o louco "retido em sua própria 
verdade [inventada pelo saber médico, cristalizador de sua identidade e de sua conduta], e, por isso mesmo, afastado dela. Estranho em relação a si mesmo, "Alienado"' (FOUCAULT, 1997[1961], p. 509).

Como fruto desta alienação produzida pelos discursos pretensamente científicos da loucura, o que se tem é a criação do homo psychologicus, enquanto foco de exercício, prático e discursivo, destes novos jogos de verdade, cuja descendência, para Foucault, se refere ao homo mente captus (FOUCAULT, 1997[1961], p. 522), enquanto invenção da linguagem psicológica da loucura alienada de sua selvageria e imprecisão desatinada, já que objetivada.

\title{
Conclusões
}

Sobre a Psicologia, é importante apresentarmos o ponto de vista de Foucault (1997[1961], p. 522), a seguir:

\begin{abstract}
Em nossa ingenuidade, imaginamos talvez ter descrito um tipo psicológico, o louco, através de cento e cinqüenta anos de sua história. Somos obrigados a constatar que, ao fazer a história do louco, o que fizemos foi - não, sem dúvida, ao nível de uma crônica das descobertas ou de uma história das idéias, mas segundo o encadeamento das estruturas fundamentais da experiência - a história daquilo que tornou possível o próprio aparecimento de uma psicologia. E por isso entendemos um fato cultural próprio do mundo ocidental desde o século XIX: esse postulado maciço definido pelo homem no ermo, mas que o demonstra bem: o ser humano não se caracteriza por um certo relacionamento com a verdade, mas detém, como pertencente a ele de fato, simultaneamente ofertada e ocultada, uma verdade .
\end{abstract}

Neste sentido, reduzida a sua essência à positividade de um saber antropológico moderno, que a coisifica como objeto de verdade, a loucura passa a ser foco privilegiado de categorização das doenças mentais, na consolidação dos saberes psicológicos.

Esta análise crítica não é libertadora, já que não existe exterioridade aos saberes produzidos no curso da História. Portanto, não há um espaço de neutralidade no qual o sujeito possa se posicionar, seja aquém ou além ao campo histórico de embate dos saberes do qual emerge e que o atravessa. Assim, é impossível que qualquer sujeito, no curso da História do Pensamento da $\mathrm{Hu}$ manidade, se desvincule liberadamente das tensões epistêmico-discursivas nas quais se encontra imerso - produzido e produtor - nelas posicionado. Por outro lado, este tipo de análise nos permite a reflexão estratégica de nossa posição na cartografia de tais verdades e dizeres.

Neste sentido, compreendemos que, ao analisarmos a arqueologia da Psicologia enquanto saber que, historicamente, pretende estudar, dentre outras concepções, a consciência do indivíduo, nos parece imprescindível que, 
ao dispositivo dos saberes dos estudos da consciência dos saberes psis, seja anexada, tanto por parte do cientista que o produz como do lado dos sujeitos que a eles são submetidos, o que podemos denominar de uma "consciência dos arranjos epistêmicos" que os produzem.

Assim, talvez seja possível evitarmos os efeitos, que nos parecem na prática, deletérios, de cristalização do ser em aspectos personalistas, a partir de pressupostos epistêmicos que atam discursivamente o sujeito psicológico a enunciados de uma interioridade que o escraviza, na medida em que não leva em conta a história dos discursos psicológicos, produtores de enunciados como o de "personalidade, essência, sujeito, eu interior, eu fechado", dentre outros.

Desta maneira, é possível que os estudos arqueológicos de Foucault sirvam no questionamento e eventual desconstrução da pressuposição naturalizada da $p s i$ qué enquanto emanação inerente à estrutura dos corpos e das almas dos homens, ao levar em conta a sua produção pela história dos saberes, em seus efeitos encarnantes sobre os indivíduos, conforme intencionamos demonstrar neste artigo. 


\section{REFERÊNCIAS}

DEFERT, D.; EWALD, F. (Org.). Dits et écrits - IV. Paris: Gallimard, 1994.

ESCOBAR, C. H. (Org.). O Dossier - Últimas Entrevistas. Rio de Janeiro: Taurus, 1984.

FOUCAULT, M. A História da Loucura na Idade Clássica (1961). 5. ed. São Paulo: Perspectiva, 1997.

- A Arqueologia do Saber (1969). 5. ed. Rio de Janeiro: Forense Universitária, 1997. 1987. . Vigiar e Punir: nascimento da prisão (1975). 14 ed. Petrópolis: Vozes,

. História da Sexualidade: a vontade de saber (1976). 11. ed. Rio de Janeiro: Graal, 1993. v. 1.

. A Ordem do Discurso (1970). 6. ed. São Paulo: Loyola, 2000.

MERLEAU-PONTY, M. Fenomenologia da Percepção (1945). 2. ed. São Paulo: Martins Fontes, 1999.

SILVEIRA, F. A.; FURLAN, R. Michel Foucault e a Constituição do Corpo e da Alma do Sujeito Moderno. 2001. Dissertação Mestrado - Pós-Graduação em Psicologia do Departamento de Psicologia e Educação da FFCLRP - USP, São Paulo, 2001. Disponível em: http://www.teses.usp.br/teses/disponiveis/59/59137/ tde-17052004-120350. Acesso em: 15 jan. 2009.

Corpos Sonhados-Vividos: A Questão do Corpo em Foucault e MerleauPonty (2005). Tese Doutorado - Pós-Graduação em Psicologia do Depto. de Psicologia e Educação da FFCLRP - USP. Disponível em: http://www.teses.usp. br/teses/disponiveis/59/59137/tde-09062006-162253/. Acesso em: 15 jan. 2009.

Recebido em: fevereiro de 2009

Aceito em: maio de 2009 